\title{
Travel guide to Textile Architecture
}

\author{
Dipl.-Ing. Architect Katja Bernert* \\ * Mehler Texnologies \\ Rheinstr.11, 41836 Hueckelhoven, Germany \\ e-mail: Katja.Bernert@lowandbonar.com, web page: https://www.mehler-texnologies.com
}

\begin{abstract}
The presentation shows a couple of recent textile architecture projects under the header: Places we'd rather be.

The itinerary will start at the Green School in New Zealand: class room units, wrapped in fabrics, scattered around a beautiful landscape. The textile shapes are meant to trigger the pupils' open minded way of working and learning. From there we'll travel towards Vietnam and Thailand with classical beach architecture. In India we'll explore the statue of Unity from a shaded view under a textile roof. Then we'll do some rocket science in order to reach a near galaxy. Thankfully we'll find shelter under a textile roof. On our next stop in Qatar we'll check on the football stadia for the upcoming football world cup: we'll concentrate on the convertible textile roof of Al Wakrah stadium. Having enough of desert and dunes, we're looking for a place to relax. We'll find this in the Okavango Delta in Botswana. The accommodation at the Kwai Lodge is arranged in tents that are made of the same material type as the Green School in New Zealand which was the starting point of our journey.
\end{abstract}

The Carbon Dioxide for this trip would probably weigh as much as the fabric for Poznan Stadium. There is of course a far more sustainable way of finding relaxation under fabric roofs: if we got used to satisfying our wanderlust in a more eco-friendly radius we can still visit "Die Therme" in Bad Wildbad, catch-up our cultural backlog in Bad Hersfeld or -with smaller children and Karl May loving travellers- in Elspe.

Surely these kinds of fabric destinations can be found near the home offices of Textile Architecture travellers all over the world. Talking of mobile work places: the Central European traveller can quickly make a stopover at Frei Otto's roofs for Wilkhan and buy some new office furniture. 